\title{
The Elderly and Their Experience in Brazil
}

\author{
Alice $\operatorname{Itani}^{1}$ \\ ${ }^{1} \mathrm{PhD}$ in Sociology, professor at Unesp, Universidade Estadual Paulista, Brazil. \\ Correspondence: Alice Itani, Av. Higienópolis, 195 São Paulo 01238-001, Brazil
}

Received: October 23, 2014

Accepted: November 7, $2014 \quad$ Available online: December 11, 2014

doi:10.11114/ijsss.v3i1.606

URL: http://dx.doi.org/10.11114/ijsss.v3i1.606

\begin{abstract}
What is the experience of the elderly in Brazil like? This question merits discussion. Concerns with regard to protecting and caring for the elderly have changed in recent decades. The elderly population currently represents around $13 \%$ of the total, and the tendency is that this figure will rise over the next few decades. Since the Brazilian Constitution of 1998, a body of legal instruments has been established for protecting the rights of the elderly. This paper tries to analyze this experience of the elderly in relation to public policies. The public policies that have been introduced over the last three decades have contributed towards the elderly becoming more independent. The work is also based on data and studies that have been developed about the elderly and ageing. It was found that the elderly have become more independent, despite the obstacles.
\end{abstract}

Keywords: elderly, rights, autonomy, social practices, health promotion, prejudice, frailty

\section{Introduction}

The experience of ageing is changing in the world. The increase in life expectancy at birth is one of the most remarkable facts of the last century, particularly after the Second World War. Data show that life expectancy increased from 48 years to 68 years in the period of 60 years between 1950 and 2010, according to figures taken from the 2012 State of the World Population Report, produced by the United Nations Population Fund (UNFPA) (2013). This ageing process is occurring in all countries. In the case of Brazil, life expectancy has increased from 74 to 83 over the last ten years (IBGE, 2013). Those over 60 represent around $12.6 \%$ of the Brazilian population today, in other words, around 25 million people, according to information from the PNAD 2012 (IBGE, 2013). There is a growing tendency that this population in Brazil will increase.

Concern with the ageing of the population has warranted a great deal of attention over the last three decades. This concern, however, is also centered on responsibility for the charges associated with this ageing process. Given the dependence of the elderly population on the care service system, the public costs that this represents are being questioned, as Tennstedt and McKinlay (1994) analyze. There is also the fact that around half the elderly population in the world has some degree of disability. Only one third of the countries in the world, which correspond to just $28 \%$ of the world's population, have extensive social protection plans that cover the branches of social security. The disability associated with the elderly population is explained by their frail state and economic dependence. But these notions of disability associated with frailty and dependence need to be discussed.

What is the experience of the elderly in Brazilian society like? The elderly as a collective subject live out their experience of ageing, like other stages in their lives, with a certain degree of autonomy. It is argued that autonomy, as it is referred to here, is similar to the concept that was developed by Castoriadis (1975), who thought of the individual as instituted and also as capable of instituting themselves, which is a decision, an individual right. In other words, an individual is capable of taking their place in society as an instance of decision, a subject with rights. This autonomy, however, cannot develop except in a society that is autonomous and seeking to develop as such, as a political prospect within a process dynamic. This autonomy is also seen in the capacity for constructing collective projects, a capacity for transforming, by appropriating the experience. The elderly today, and certainly more than in other periods, have more experience because of the number of relationship networks they have developed and drawn together over their lifetimes and the number and duration of their life experiences. This autonomy is spread as practices in social relationships and can be analyzed by way of political, socio-economic and emotional indicators.

The Brazilian Constitution of 1988 was a milestone in terms of social rights, as seen in the resulting public policies. But 
were these policies sufficient to enable dignified conditions, protection and a healthy quality of life? Social policies can be analyzed from the basis of public policies. The objective of this paper is to analyze the experience of the elderly in Brazilian society on the basis of the country's public policies with regard to the elderly. It seeks to contribute to debate on the issue. It is based on data and studies of the elderly population. Above all the paper discusses the notions of disability as associated with frailty and dependence. Experience is analyzed from the aspect of public policies, considering legislation and the programs that have been developed and the social practices that are seen because of the ways in which social individuals produce health.

\section{The Elderly: Between Frailty and the Subject of Rights}

The elderly population is mentioned in the literature of health sciences, which stresses their frailty as being an important factor in this phase of life. There is even a measure of this frailty, which is assessed on a scale that was developed by Canadian studies, known as the Edmonton Frail Scale, and which comprises nine items: cognitive, general health, functional independence, social support, medication use, nutrition, mood, continence and functional performance, as outlined by Rockwood et al. (2004). There is also a Cumulative Load Index, which defines the accumulation of these deficits, as structured by Rockwood et al (2004) and Rockwood \& Mitniski (2007) and the Biological Syndrome Model, developed by Fried et al (2001), which defines frailty as being when three or more of these conditions are present, like a low level of physical activity, involuntary weight loss, slow walking speed, poor physical strength, etc. Also present is the frailty associated with the vulnerability of the elderly, because of some illnesses from which they suffer, as well as their functional and economic dependence.

Environmental factors such as air pollution have a negative effect on these groups and make them more vulnerable than other groups. The higher incidence of cardio-respiratory diseases was analyzed by Gouveia \& Fletcher (2000), Martins et al. (2002), Holguim et al. (2003). There has been an increase in the tendency of the population over 75 to die from respiratory diseases, which can be attributed to the increase in fine particulate matter and sulfur dioxide in the air, since the smaller the particles the greater their capacity for penetrating the lower airways and pulmonary alveoli. Cardiovascular deaths are associated with carbon monoxide levels, as analyzed by Gouveia \& Fletcher (2000) and Gouveia et al. (2006). The effects of climate change are also cited, such as stress with an increase or decrease in temperature, loss of community and culture, the occurrence of storms and rainfall (Cameron, 2011; Lankford et al, 2011; Megret, 2011). Levers et al. (2006), in a review of literature relating to the elderly population, emphasize that frailty is considered to be a clinical phenomenon associated with age. It presents, itself, however, as a cumulative process resulting from deficits, above all those of the musculo-skeletal system, that result in a reduction in movement capacity, walking around in activities relating to looking after oneself, such as feeding and hygiene, and physical activities, as was studied by Chin et al. (1999), Fried et al. (2001), Nourhashemi et al. (2001), or reduced mobility and agility, as defined by Brown et al. (1995) and Raphael et al. (1995).

Indeed, there is no way of denying the physical ageing of the body, which is an unquestionable and visible fact. Disability associated with frailty, however, seems to be a notion that is socially constructed. But just as in other phases of life, biological conditions have to be taken into account. It also has to be considered that studies into frailty have arisen above all from studies into patients who are in either permanent care situations, as in the case with Brown et al. (1995), Raphael et al. (1995) and Chin et al. (1999), or in temporary care. As a result, the representation of disability related to frailty is negatively produced. But, frailty is considered to be multidimensional and resulting from a set of factors that are physical, psychological, socio-economic and related to the age band. Kaufman (1994) also points out that frailty is a being that is socially produced in discourse on health care. The analysis is found in the debate between medicalization and autonomy, which are concurrent perspectives. Based notably on cases of looking after the elderly in North American care centers, Kaufman (1994) found contradictory discourses resulting from a 'medicalization' as a care practice and also contradictory discourses between supervision and individualized control.

Frailty is also associated with cognitive loss, considered to be a decline in intellectual functions, such as thinking, memory, argumentation and planning. But studies, such as those by Robertson et al. (2013), show that there is a vast range of states considered to represent cognitive loss, which range from minor forgetfulness to dementia. The progression in this decline, which is associated with an increase in frailty, still cannot be stated, as analyzed by Robertson et al. (2013). There are many factors that need to be analyzed in order to characterize this loss.

The presence of disability is a burden on the individual, the family, the health system and society. But functional incapacity and physical, cognitive and sensory limitations are not the inevitable consequences of ageing. The prevalence of disability increases with age, but age alone does not portend disability, as the studies of Lollar and Crews (2003) and Crews (2011) show. If one takes into account studies with different population groups, we see that women, minorities and people from low socio-economic backgrounds are particularly vulnerable, as analyzed by Freedman, Martin and Schoeni (2002) and Schoeni et al. (2004). Regardless of their etiology, people suffering from disabilities are at greater 
risk of succumbing to health problems and the like, as Lollar and Crews (2003) argued. This is a process and, as such, does not begin at any particular age band, but develops over the years, and derives from socio-economic conditions, preventive care and health promotion, from undertaking physical and cultural activities, etc.

Furthermore, another controversial aspect is the notion of the elderly associated with charges and financial dependence. However, the relationship between old age and financial dependence cannot always be established. In the case of Brazil, this relationship can be questioned, according to the data from the study by Camarano (2002), which show that there is no direct relationship between age and economic dependence. On the contrary, it is the income of the elderly that supports many families. Most elderly people are also responsible for their own homes and have an average age of 69, 3.4 years of education and an average monthly income of $\mathrm{R} \$ 657.00$ (IBGE, 2010). In the period analyzed (1995) the main source, if not the biggest source of family income, came from a pension, with young people being the dependents. Fernandes and Garcia (2010) also show that women are more exploited on many levels by intra-family violence, with the responsibility for taking care of children, as demanded by their children, including the financial costs.

In the case of Brazil, disability cannot be considered as being exclusive to the elderly population. Data from the IBGE 2008 report (2010a) show that $45.5 \%$ of the elderly consider their health to be good or very good. Only some $12.6 \%$ of this group considers their state to be bad or very bad. Of the population who reported health problems, $28.3 \%$ reported chronic diseases, with hypertension, back pain and rheumatism being among the most cited. In the 60-year old population, $15.2 \%$ reported some difficulty in carrying out everyday tasks, such as feeding, bathing or going to the toilet, while $27 \%$ of this group have difficulty in walking 100 meters. But more than one third $(38.1 \%)$ of the population aged 65 or older did not perform any physical activities (IBGE, 2008).

\section{Regulatory Instruments and Public Policies}

Considering Brazil is a young country it has also been paying attention to the question of ageing over the last three decades, since the Brazilian Constitutional Charter of 1988. The debate of the last few decades about ageing in the world has resulted in institutional and legal parameters. From the General Assembly of the United Nations has come political, economic and cultural guidance that can guarantee that the elderly continue with their contribution to society in an active and productive way. Since 1973, the General Assembly has been drawing attention to the need for protecting the rights of the elderly. In 1982, in the first UN Assembly on Ageing, held in Vienna, the Vienna International Plan of Action on Ageing, was drawn up, involving 124 countries, with principles and economic and cultural strategies, as guidance for the public policies of countries. In this plan, the family was established as being the fundamental unit for maintaining and protecting the elderly, with public policies for ensuring they receive complete assistance that enables their contribution and participation in the formulation and implementation of such public policies.

The Ottawa Charter, which was prepared at the first International Conference on Health Promotion in 1986, emphasized concern with the quality of life, equity, democracy, participation and citizenship, linking public policies, communities and individuals. Health was defined as a positive concept, as a resource for life. Health promotion seems to be a process for enabling the community to operate in improving quality of life. The participation of the elderly is relied on for searching for this resource for life, which links both social and personal resources.

It is a fact that the figure of the elderly person has appeared in Brazilian legislation since the start of the $20^{\text {th }}$ century, above all in the Civil Code of 1916 and the Criminal Code of 1940. But only at the end of the last century did the prospect of a minimum income for the elderly appear, with Law 6179 of 1974, which establishes a monthly income for life, and other decrees and ordinances related particularly to retirement issues. But a set of specific instruments has been established over the last few decades based on the Brazilian Constitutional Charter of 1988, in which fundamental rights are reinforced and guaranteed. Constructed with the participation of different segments of Brazilian society, it came out of the debate about the subject as the major Brazilian legal instrument, and guarantees that every citizen is able to exercise their social and individual rights, which are translated as freedom, security, well-being, development, equality and justice. These are held to be the supreme values of a fair, fraternal and pluralistic society in which there is no prejudice. It also ensures universal and full right to health and universal and equitable access to health promotion, protection and recuperation services and actions, thus guaranteeing total care. As a result, many instruments follow the principles of these rights. They are Law 8842 of 1994, regulated by Decree 1948 of 1996, which established the National Policy for the Elderly; Law 10,741 of 2003, which approves the Statute of the Elderly; and Ordinance 2528 of 2006, which approves the National Health Policy for Elderly People, instituted by Ordinance 1395 of 1999 and reformulated by Ministerial Ordinance 2528 of 2006. We can also mention Law 10,098 of 2000, regulated by Decree 5296 of 2004, which guarantees an accessible environment for locomotion. The Action Plan for Old Age, based on Active Ageing, only appeared in 2004. 
The National Policy for Elderly People (PNI) of 1994, regulated in 1996, is a basic instrument of public policy. This policy was a specific attempt to reinforce the social rights of the elderly, with the perspective of creating conditions to promote their autonomy, integration and participation in society. It starts from the premise that the ageing process involves the whole of society. This policy emphasizes that one of the principles of the duty of the family, society and the State is that of ensuring the citizenship rights of the elderly, thus guaranteeing their participation in the community and defending their dignity, well-being and right to life. The guidelines of this policy establish, among other things, inter-generational contact and the occupation and participation of the elderly in the formulation of public policies. It also seeks to link the actions of the different bodies involved in order to prioritize care and political and administrative decentralization into service provision bodies. In this sense the Integrated Governmental Action Plan (PIAG) for the development of the National Policy for Elderly People $(P N I)$ outlines a public policy from the perspective of implementing integrated actions within those provided for in this policy.

So in order for the actions of the National Policy for Elderly People to be implemented, specific public bodies were set up for the protection of the rights of the elderly. Such is the case with the specialist public prosecution offices, the Council for the Elderly, the specialist police stations for protecting the elderly, and others. The purpose of the National Council of the Elderly, provided for in the PNI, which was created by Decree 4227 of 2002 and Decree 5109 of 2004, as a collegiate body, is to prepare directives for formulating and implementing policies for protecting the rights of the elderly. It is also to oversee and assess the implementation of the National Policy for the Elderly and encourage the creation of state and municipal councils. The specialist police stations were created by the states to serve the elderly.

Among the relevant aspects discussed and established is the notion of health promotion. Considering health as the result of a social production process, this concept is fundamental to the development of public policies. Health as a universal and full right, as provided for in the Constitutional Charter, is the basis of the creation of the Sistema Único de saúde SUS (Brazilian Single Health System). It was set up by Law 8842/1994, Decree 1948/1996 and Ministerial Ordinance 1395 , considered as a milestone along the path to another perspective of policy attention to collective health, the implementation program of SUS is unique and exemplary. It should be stressed that the creation and implementation of the SUS and many other health policy programs also resulted from the efforts of health professionals and the participation of defense institutions. Within a sector strategy for re-shaping the health care model it established the Family Health Program $(P S F)$ that aims to establish a relationship link with the community, from an inter-sector perspective, and one that falls within the assumptions of the Family Heath Strategy $(E S F)$. To make these actions operational, the states created Elderly Heath Care Reference Centers, based on Ministerial Ordinance 249/SAS/MS, of 2002. In 2008, 47.7\% of all households were registered in this program (IBGE, 2010).

The Statute of the Elderly was established in 2003, with greater attention being paid to universal and equitable access to health promotion services and actions. This Statute attempted to provide backing for the actions of the state and society on behalf of the needs of the elderly population, by guaranteeing complete health care for the elderly. This statute also provides for medication, orthoses and prostheses to be supplied free of charge. Even the National Health Policy for the Elderly (PNSPI) established in 1999, reformulated in 2006, aims to promote active and healthy ageing, with total and integrated health care for the elderly. It incorporates the active ageing strategy, which it considers to be a process for improving conditions for promoting health. Within the basic guidelines of this PNSI policy are the promotion of an active and healthy old age and the maintenance and improvement of the functional capacity of the elderly. Health promotion and preventive healthcare are basic points that are reinforced by the care to be taken in preventing illness, in helping those who get sick recuperate, and even in rehabilitating those whose functional capacity may be restricted. Above all, these instruments reinforce the need to promote the autonomy of the elderly.

Two other instruments were also established within the scope of health promotion policies, like environmental education and accessibility. One of the precepts of the fundamental objectives of environmental education is that of developing an integrated understanding of the environment, involving ecological, psychological, legal, political, social, economic, scientific, cultural and ethical aspects, all of which can be achieved by way of the dissemination of information and debate about environmental issues. The instrument aims to promote a healthy old age, maintenance and improvement of the functional capacity, illness prevention and the guarantee of remaining in the environment in which they live and exercising their functions in society. Within urban public policies, the right to locomotion and mobility in cities is the object of regulation in Law 10098/2000 that establishes rules for the accessibility of people suffering from some form of disability. The legislation is directed at accessibility in the city for people in general who suffer from a disability, like the blind, people in wheelchairs and those with reduced mobility.

International references were also important in this. In the second UN Assembly on Ageing in Madrid, held in 2002, The Madrid International Plan of Action on Ageing was prepared, which is a policy launched with the expectation of guaranteeing the security, dignity and participation of the elderly as citizens. As a guidance instrument, the plan established three basic principles: the active participation of the elderly in society, health and well-being promotion, and 
the creation of an environment favorable to ageing. The World Health Organization (WHO) has scheduled actions that enable improvements in service and care programs for this population group. For this UN meeting in 2002, the WHO prepared a health policy guidance document, "Active Ageing: a policy framework". The notion of active ageing seems to be a process of improving health, participation and security opportunities, with the objective of improving quality of life as people get older. In this process, social, economic and biological determinants are taken into account, stating the principles of people's independence, participation and dignity.

On this same United Nations path of action, also in 2010 the UN Human Rights Council was formed, with the purpose of specifically looking after issues relating to the rights of the elderly. In the case of Latin America, the topic was also the object of the outlining of international instruments that can reinforce and help with public policies in the region. The 2008 meeting of the United Nations Special Committee for Latin America and the Caribbean (CEPAL) and the Organization of American States (OAS) helped structure documents for each of the component countries.

The Brazilian Old Age Action Plan (Plano de Ação para o envelhecimento PAE) is published as a guideline document that contains strategies and recommendations. The Plan establishes principles for implementing policies for old age. Among them two can be singled out: the duties of the family as a unit for maintaining and protecting the elderly; and the duties of municipal and state directors in their public policies to ensure full assistance for this population, by preparing people for the later stages of their lives. This Plan also emphasizes participation, which must be provided as an opportunity for contributing to the development of the country, and active participation in the formulation and implementation of public policies. It provides for responsibilities to be attributed to government and non-governmental bodies and to all those who are responsible for the elderly. It also stresses the need for special care for vulnerable groups, like the very poor, women and those living in rural areas.

Another important aspect to be considered in the autonomy of the elderly is with regard to financial protection. The Continuous Provision Benefit (BPC), which was instituted by the Brazilian Constitution of 1988, was regulated by Law 8743/1993, and then regulated again by Decree 6214 of 2007. It attributes an amount of a minimum salary to people over 65 years of age and those suffering from disabilities. This benefit is an advance on the Lifetime Monthly Income $(R M V)$, which was instituted by Law 6179/1974, which provides some social security protection for those over 70 and for invalids, but only providing they have made some pension contributions. The $B P C$ protects all citizens without income, even those who have made no pension contributions. It considers that the absence of any pension contribution does not necessarily mean that a person is not a worker or has no relationship with work or the provision of a service. This is because there is a considerable number of workers whose employment has never been officially registered in their work-record booklet, whether as service providers, many of whom have an employment relationship, or as self-employed, etc. In order to receive the benefit, the family or individual income is assessed and this enables a minimum income to be paid, which contributes towards providing the elderly with a minimum amount of support.

The importance of environmental factors in the quality of life of the elderly can also be seen by the attention attributed to the environment in the agenda of the WHO. The edition of the guiding document, "Global age-friendly cities: a guide", in 2008 is an example of this. The initiative of the document originated from the Brazilian experience, which started in Rio de Janeiro, with a program for improving the quality of urban life, a guiding perspective for public policies that involve the city as a friendly environment. A friendly city is one that stimulates an active life by improving opportunities for health, participation and security in order to increase quality of life. Structures and services are privileged so they become accessible to all groups that have different needs and degrees of capacity. Cities are considered to be the center of cultural, social and political activities, and the source of new ideas, products and services that will influence other communities and, therefore, the world. However, in order to be sustainable it is understood that cities must offer structures and services that provide well-being and productivity for their residents and environments that support and train them in order to compensate for their physical and social alterations. Making cities friendlier is a necessary response to promoting well-being.

Progress is being made, therefore, regarding elderly people. But the establishment of effective actions takes time. On the one hand, not all regions have bodies for protecting the rights of the elderly. Encouragement for groups of elderly people to become involved with public policies, collegiate bodies, and intersector actions depends on actions that are still at an early stage or just beginning to be implemented in many regions in Brazil. On the other hand, equity practices still have a long way to go before they break down the inequality and differences that exist in social relationships. These relationships are also dependent on public policies.

\section{The Elderly and Their Experience in Social Practices}

There are public policies for the elderly and these have assumed health to be a right. Some data go to corroborate this statement, such as the demand for health services, the right to life and access to these services. The IBGE/PNAD 2008 Health Report (Relatório de saúde) shows there to be an increasing use of public health services by the elderly 
population. Approximately $56.8 \%$ of the population uses a care center or health center, with $82.3 \%$ of the population over 65 years old using health services or a public health center in the last year. There was an increase in the search for public health and disease prevention, particularly among the lower income population. On the other hand, about $25.9 \%$ of the population has a private health insurance, i.e. 49.2 million in 2008 , and about $29.7 \%$ of the elderly over age 65 have health insurance, i.e. a third of this elderly population.

However, this does not mean that their living conditions are excellent. The elderly population has stated its condition and its rights, despite a marked content of violent social practices. This is an old issue: violence against life, integrity, well-being and rights, which emphasizes a host of problems to which the elderly are exposed. The most noteworthy is that this violence places a question mark against their lives, which is clearly evident in their morbidity and mortality rates. Analyzing the epidemiological data from studies carried out into the causes of death in the elderly between 1990 and 1998, Minayo (2003) saw that within them there are three most marked causes: those resulting from traffic and transportation accidents, which represented $55.8 \%$ of all deaths in 1998; those resulting from falls, which represented $16.6 \%$ of the deaths; and those resulting from murder, $13.7 \%$.

Among the cases involving admission to hospital are frequent falls in the home, or while crossing the street, or when catching a bus. Information, taken from the Information System on Hospital Admissions Data from the Health Ministry in 2008, also emphasizes the figures of the previous decade: 122,000 elderly people were admitted to hospital $-15.9 \%$ of all the admissions, most of them resulting from falls and transportation accidents. The most recent data from 2009 and 2010 in the 2013 Violence and Accident Surveillance System Report (Viva), show the same incidence.

From these data it is possible to separate out the problems found in the Brazilian scenario, like domestic and urban violence. From the data taken from the 2008 Notifiable Harm Information System, of the Violence and Accident Surveillance System (Viva), there were 3593 notifications from 524 Brazilian municipalities, 52.3\% involved females and $78.8 \%$ of the cases result from events that occurred within the home. The cases most reported were physical abuse (67.7\%), psychological violence $(29.1 \%)$ and negligence. Of the 5568 notifications of violence against the elderly aged 60 or more in 2009 and 2010 in the Viva System, most are considered to be repeat violence, in other words, the violent event had already occurred previously. Domestic violence is caused by male aggressors and mostly by sons (32.6\%) and partners (14\%), with women being the greatest victims, as analyzed by Mascarenhas et al. (2012) from 2010 data.

This fact reinforces the study of Fernandes \& Garcia (2010) who, in analyzing the various types of violence to which the elderly are exposed, show that violence against the elderly is expressed in a variety of ways, but it is within families that it occurs in a more pronounced way, with women being the biggest victims. Women are more exposed, also, because their work is exploited at various levels, whether being responsible for financial charges, above all when they live in the same house, or whether looking after grandchildren or doing domestic chores for their children. This means that at this stage in their life they experience a large physical and psychological burden.

This is a type of violence that is understood to be part of social relationships, the relationships between individuals and groups that take on different forms and involve different methods, but that cause physical, moral and mental damage. There is also diffuse social neglect that is present in the culture in relation to the elderly, as understood by Minayo (2003). The state is also absent with regard to rights protection programs and some families, because of financial problems, abandon old people. There are care institutions and nursing homes that are not adequately structured. One of the initiatives that has been introduced to prevent violence, considering that victims are unable to appear in person at a police station or a health care center, is the installation of a Dial Elderly service in many cities.

It is worth placing this information within the context of the degree of physical violence that affects the country. From the data from the 2008 Health in Brazil Panorama Report from the IBGE/PNAD we see that around 2.0\% of the Brazilian population, in other words, 3.7 million people, declared that they had been the victim of violence. Some regions are more implicated in this, such as the North, which had the largest percentage of victims at $2.5 \%$, and the Southeast, which had the largest number of victims, ay $1.9 \%$ of the population. The Northeast region had the lowest percentage at $1.8 \%$. Among the victims, the elderly over 60 years of age represented $8.1 \%$ of this total. The South region had the biggest incidence of victimization among people over 60 or more.

With regard to the violence resulting from urban life, the issue of urban equipment is still an obstacle to making the city a friendlier place. Sidewalks full of holes lead to frequent falls and traffic lights with a very short time for crossing complicate mobility. Public transport on vehicles with very high step-up, narrow bus turnstiles that are difficult to pass through, and the speed with which the buses brusquely start off or violently brake are the reason behind many passenger falls. These obstacles to the right to free locomotion, to mobility, require that environments, the architectural conception of public equipment and accessibility, be redesigned.

In this experience it is also worth emphasizing the discrimination or prejudice that is found in daily relationships that are marked by three components. The first is social inequality. Some $1.4 \%$ of the elderly population is poor and 
Afro-Brazilian populations are found at the base of this inequality. The country managed to remove 31 million people from poverty in a decade thanks to the impact of the growth in the performance of the labor market, which was associated with the recovery in the value of the minimum salary, which increased by $93 \%$ in real terms in the last decade, as analyzed by Lavinas (2012). But, there is still a lot to be done. Almost half the Brazilian population is of Afro-Brazilian descent, according to data from the 2012 IBGE Census (IBGE, 2013): 41.7\% declared they were white, $40.3 \%$ brown, $14.6 \%$ black and $3.4 \%$ yellow-skinned or indigenous. Legal instruments against racial discrimination and the public policies that were considered to be affirmative, with specific quotas for blacks, have still to produce results.

A second component is the discrimination found in Brazilian society that involves the notion of gender. The majority of those in the elderly Brazilian population are women, or 8.9 million people, which represents $62.4 \%$ of the elderly, according to $I B G E$ data (2010). A third component is experience with stereotypes. Rodrigues et al (2007) show the frequent association of old age with loss and incapacity, which has reinforced attitudes of discrimination. Debert (2010) analyzes models and stereotypes, but those that are created at different times and have to do with different population groups start with infancy. He analyses the fact that stereotypes linked to biological degradation continue to impregnate the cultural imaginary.

This experience of the elderly deserves to be seen, as well, within a society that is considered to be young. If the composition of the population according to IBGE data (1999) is analyzed, it appears that the population between 0 and 14 years old represents about $31.6 \%$ of total, while the young population between 15 and 24 years old, is about $22 \%$ of the total. In 1996, there were 31 million young people in this age group. The relationship suffers cleavages that differentiate the different groups. The change in course in Brazilian age structure since 1970 (Carvalho et al, 2008) and increase in the elderly population, shows that inter-generational families, and especially with age groups above 60 years old, are a recent phenomenon.

\section{Final Considerations}

It is evident since the Constitution of 1988, a set of legal instruments has been acquired that shows that fundamental rights have been established and are available, such as public policies of attention, care, access to justice, and the right to belong to and participate in society. The concept of health promotion is one of the most important points in this public policy and it is beginning to spread in terms of legal instruments and public policies. Measures of accessibility, mobility and financial support make it possible to develop a perspective of collective autonomy. There is an experience of the elderly, which can be stated as a collective subject of rights, a whole being.

In a society, hitherto considered young, this inter-generational experience with an ageing population is recent. The practice of discrimination and prejudice supported by socially constructed notions of stereotypes require the deconstruction of values, ideas and notions for construction on other bases. This is a process along a path that has to be trodden by society as whole. The elderly as a subject of rights also need to be stated in the exercise of their rights. Legal instruments are necessary but not sufficient for changing the situation. It is the exercise of these rights to be followed by subjects as citizens, which can also produce values of justice and equality. Policies to promote health, as well as measures of accessibility and better living conditions, which are still in the implementation process, tend to increase the quality of life and to produce healthier life in cities.

Progress has been made in social processes that pay attention to the elderly, especially by programs for promoting health. But some public policies are still not particularly effective. On the other hand, there is a process of social production of individuals with rights. As citizenship is a construction process that also includes the exercise of a set of freedoms, civil rights, access to information, the right to work and justice, this process also requires actions by the State as well as by the whole of society.

\section{References}

Brasil. (1974). Law n. 6179/1974. Amparo previdenciário para maiores de 70 anos. Brasilia: DF. (1988). Brazilian Constitution. Brasília DF.

(1994). Law n. 8.842/1994. Política Nacional do Idoso. Brasília: DF, and Ordinance MS n. 1395/1999. (2000). Law n.10.098/2000. Estabelece normas de acessibilidade. Brasília DF.

(2002). Decree n. 4227/2002 and Decree n. 5109/2004, cria Conselho Nacional dos direitos do idoso CNDI. Brasília DF. (2003). Law n. 10741/2003. Estatuto do Idoso. Brasília DF, 2003.

. (2004). Decree n. 5130, de 2004. Regulate art. 40 of Law n.10.741/2003, gratuidade do idoso no transporte coletivo. Brasília DF. 
Brasil. (1997). Ministério da Previdência Social (MPS). Plano Integrado de Ação Governamental para o Desenvolvimento da Política Nacional do Idoso. Brasília DF: MPS.

Brasil. (2001). Ministério da Saúde. Ordinance n. 737/2001. Política Nacional de Redução de Morbimortalidade por Acidentes e Violências. Brasilia DF: MS.

Brasil. (2006a). Ministério da Saúde. Ordinance n. 2528/2006 Política Nacional de Saúde da pessoa idosa. Brasília DF: MS.

(2006b). Secretaria de Atenção à Saúde. Departamento de Atenção Básica. Envelhecimento e saúde da pessoa idosa. Brasília DF: MS. (2013). Sistema de Vigilância de Violências e Acidentes (Viva): 2009, 2010. Brasília DF: MS.

Brown, I., Renwick, R. \& Raphael, D. (1995). Frailty: constructing a common meaning, definition and conceptual framework. International Journal of Rehabilitation Research, 18(2).

Camarano, A. A. (2002). Envelhecimento da população brasileira: uma contribuição demográfica. Rio de Janeiro: IPEA,

Cameron, E. (2011). Development, climate change and human rights: From the Margins to the Mainstream? Social Development Working Paper 123, Washington DC: World Bank.

Carvalho, J. A. M. \& Rodriguez-Wong, L. (2008). A transição da estrutura etária da população brasileira na primeira metade do século XXI. Cad. Saúde Pública, Rio de Janeiro, 24(3).

Castoriadis. C. (1975). L'institution imaginaire de la socété. Paris: Seuil.

Chin, A., P. et al. (1999). How to select a frail elderly population. A comparison of three working definitions? Journal of Clinical Epidemiology, 52(11).

Comissão Especial para a América Latina e Caribe (Cepal). (2008). Seguimento Declaração de Brasília dos Direitos da Pessoa, Brasília DF: Cepal.

Crews, J. (2011). Aging, disability and public health. Public Health Perspectives on disability. Springer.

Debert, G. (2010). A dissolução da vida adulta e a juventude como valor. Horizontes antropológicos, 16(34).

Fernandes, M. G. M. \& Garcia, L. G. (2010). O sentido da velhice para homens e mulheres idosos. Saúde e Sociedade, 19(4).

Freedman, V. A., Martin, L. G. \& Schoeni, R. F. (2002) Recent trends in disability and functioning among older adults in the United States: a systematic review. The Journal of the American Medical Association Jama, 24.

Fried, L. P. et al. (2001) Frailty in older adults. The Journal of Gerontology series A: Biological Sciences and Medicine Science, 56.

Gouveia, N. \& Fletcher, T. (2000). Time series analysis of air pollution and mortality effets by cause, age and socioeconomic status. Journal of Epidemiology Community Health, 54.

Gouveia, N., Freitas, C. U., Martins, L. C. \& Marcilio, I. O. (2006). Hospitalização por Causas Respiratórias e Cardiovasculares associadas à contaminação atmosférica no Município de São Paulo. Cadernos de Saúde Pública, 22(12).

Holguin, F. et al. (2003). Air pollution and heart rate variability among the elderly in Mexico City. Epidemiology, 14.

Instituto Brasileiro de Geografia e Estatística (IBGE). (2002). Perfil dos idosos responsáveis pelos domicílios 2000. Rio de Janeiro: IBGE.

. (2008). IBGE. Projeção da população do Brasil por sexo e idade para o período 1980-2050. Rio de Janeiro: IBGE.

. (2010). Síntese dos indicadores sociais. Uma análise das condições de vida. Rio de Janeiro: IBGE.

. (2011). Pesquisa Nacional de Saneamento Básico 2008. Rio de Janeiro: IBGE.

. (2012). Atlas de Saneamento 2011. Rio de Janeiro: IBGE.

(2013). Pesquisa Nacional de Amostra de domicílios PNAD. Síntese de indicadores 2012. Rio de Janeiro: IBGE.

Kaufman, S. (1994). The Social Construction of Frailty: An Anthropological Perspective. Journal of Aging Studies, $8(1)$.

Lankford, S. M. et al. (2011). Human Rights and Climate Change. A Review of the International Legal Dimensions. Washington DC: The World Bank.

Lavinas, L. (2012). Medindo o grau de aversão à desigualdade da população brasileira. Rio de Janeiro: UFRJ. 
Levers, M., Estabrooks, C. \& Kerr, J. C. R. (2006). Factors contributing to frailty. Literature review. Journal of Advanced Nursing, 56(3).

Lollar, D., Crews, J. \& John, E. (2003). Redefining the role of public health and disability. Annual Review of Public Health, 24.

Martins, L. C., Latorre, M. R., Cardoso, M. R., Gonçalves, F. L., Saldiva, P. H., \& Braga, A. L. (2002). Air pollution and emergency room visits due to pneumonia and influenza in São Paulo. Revista de Saúde Pública, 36.

Mascarenhas, M.D.M. et al. (2012). Violência contra a pessoa idosa: análise das notificações realizadas no setor saúde Brasil 2010. Ciencia e Saúde Coletiva, 17(9).

Megret, F. (2011). The Human Rights of Older Persons: Growing Challenges, Human Rights Law Review, 11(1).

Minayo, M. C. S. (2003). Violência contra idosos: relevância para um velho problema. Cadernos de Saúde Pública, 19(3).

Nourhashemi, F. et al. (2001). Instrumental Activities of daily living as a potential marker of frailty: A study of 7364 community-dwelling elderly women. Journal of gerontology: Medical Sciences, 56(7).

Raphael, D. et al. (1995). Frailty: a public health perspective. Canadian Journal of Public Health, 86(4).

Robertson, D. A., Savva, G. M. \& Kenny, R. A. (2013). Frailty and cognitive impairment. A review of the evidence and causal mechanisms. Ageing Research Review, 12.

Rockwood, K. et al. (2004). Prevalence, attributes, and outcomes of fitness and frailty in community-dwelling older adults: report from the Canadian study of health and aging. The Journal of Gerontology series A: Biological Sciences and Medicine Science, 59(12).

Rockwood K. \& Mitnitski A. (2007). Frailty in relation to the accumulation of deficits. The Journal of Gerontology series A: Biological Sciences and Medicine Science, 62(7).

Rodrigues, R. A. P. et al. (2007). Política Nacional de atenção do idoso e a contribuição da enfermagem. Texto Contexto Enfermagem, 16(3).

Schoeni, R. F., Martin, L. G, Andreski, P. M., \& Freedman, V. A. (2004). Persistent and growing socioeconomic disparities in disability among the elderly: 1982-2002. American Journal Public Health, 95(11).

Tennstedt, S. L. \& Mckinlay, J. B. (1994). Frailty and its consequences. Social Science Medicine, 38(7).

United Nations Development Programme (UNDP). (2013). Report of Human Development. Brasília: UNDP. (2013). UNDP. Atlas do desenvolvimento humano no Brasil 2013. Brasília DF: UNDP.

United Nations Population Fund (UNFPA)/Helpage. (2012). Internacional. Ageing in the 21th Century. UNFPA (2013). UNFPA. State of world population.

United Nations (UN). (1982). Vienna International Plan of Action on Ageing. Vienne: UN.

_. (2002). The Madrid International Plan of Action on Ageing, Madrid: UN (2005). World Population Ageing: 1950-2050. Washington DC: UN.

World Health Organisation (WHO). (2002). Active Ageing: A Policy Framework. WHO.

_. (2005).The World is Fast Ageing - Have We Noticed? Washington DC: WHO.

. (2008). Global age-friendly cities: a guide. Washington DC: WHO/PAHO.

. (2011). What is the public health implications of global ageing? Washington DC: WHO.

. (2012). Knowledge translation. Framework for ageing and health. Washington DC: WHO.

\section{(c) $)_{E Y}$}

This work is licensed under a Creative Commons Attribution 3.0 License. 